\title{
Developing Multilingual Competence and Cultural Awareness through Forms of Non-Formal Learning: A Contribution to Sustainable Employability, Active Citizenship and Social Inclusion
}

\author{
Anabela Valente Simões \\ ESTGA | CLLC, University of Aveiro, Portugal
}

\section{Abstract}

We live in a fast-changing world, where breakthrough technological advances have not just disrupted industries but also changed the way we live, work and learn to a degree humankind has never experienced before. As the modern workplace becomes ever more global and interconnected, proficiency in foreign languages (FL) assumes a fundamental role in international business relations. Simultaneously, being able to navigate culturally diverse environments, i.e., understanding how international stakeholders think, work, and express themselves through their attitudes and behaviours is of paramount importance as well. These challenges also raise pressing questions: How can we prepare learners for a global world in constant evaluation? How can we help them develop $21^{\text {st-century skills as important as }}$ critical thinking, creativity, communication, adaptability, digital literacy and cross-cultural understanding? In May 2018, the Council of the European Union (CEU) adopted a Recommendation on Key Competences for Lifelong Learning, a framework that attempts to establish a common understanding of competences needed in the present moment and the future, by emphasising the inter-relatedness of knowledge, skills, attitudes and values. An important reference tool for education and training stakeholders, this recommendation identifies the following key competences: 1) Literacy competence; 2) Multilingual competence; 3) Mathematical competence and competence in science, technology and engineering; 4) Digital competence; 5) Personal, social and learning to learn competence; 6) Civic competence; 7) Entrepreneurship competence; and 8) Cultural awareness and expression competence. The EU Member States are, thus, encouraged to prepare their citizens for changing labour markets and active citizenship in more diverse, mobile, digital, and global societies, and to develop learning at all stages of life. While teacher-guided approaches will remain an important pedagogical practice, the main approach to teaching key competences is through providing learning environments that facilitate active learning, i.e., student-centred settings where open-ended problems and challenges can be solved through 
debate, experimentation, exploration, and creativity. This paper aims to narrate a non-formal activity carried out within a Business English Communication course taught at the Higher School of Technology and Management of the University of Aveiro (Portugal), in collaboration with an international group of volunteers from the European Solidarity Corps. This initiative sought to contribute to the development of some of the key competences for lifelong learning, especially multilingual skills and cultural sensitivity and expression, but also digital skills and personal and social skills of the participants.

Keywords: intercultural communication, FL teaching and learning, competences development, $21^{\text {st-century skills }}$

\section{Introduction}

Education is no longer about teaching students something alone; it is more important to be teaching them to develop a reliable compass and the navigation tools to find their own way in a world that is increasingly complex, volatile and uncertain. Our imagination, awareness, knowledge, skills and, most important, our common values, intellectual and moral maturity, and sense of responsibility is what will guide us for the world to become a better place. -Andreas Schleicher, OECD Education Directorate

We live in a fast-changing world, where breakthrough technological advances have not just disrupted industries but also changed the way we live, work and learn to a degree humankind has never experienced before. This is a time characterised by interdependence among nations, where socioeconomic, linguistic, and cultural diversity is the foundation on which societies are built; a time of global communication and decentralisation of power, which is accelerated by social media, emerging nationalism, and increasing incidents of terrorism; a time where workplaces have become more open, flexible and transparent and teamwork is highly valued (OECD, 2019). In its Employment Outlook 2019 report, the Organisation for Economic Co-operation and Development projected that one-third of all jobs worldwide would likely be transformed by technology by 2030 (OECD, 2019). In early 2020, the World Economic Forum (WEF) adverted that the world was facing a "reskilling emergency" (Zahidi, 2020), then later, six months into what became a global pandemic, WEF reinforced that $50 \%$ of all employees will need reskilling by 2025 (Whiting, 2020). To tackle all of these changes, we need to continuously develop competences that allow us to successfully manage the challenges posed by the many transitions taking place in our work, in our personal lives, and society. Above all, we need too to learn how to deal with uncertainty, nurture resilience, develop on a personal level, build successful interpersonal relations, and learn how to learn (Sala et al., 2020). 
This need, however, poses a quite complex question: how can we prepare ourselves for jobs that have not yet been created, technologies that have not yet been invented and problems that we don't yet know will arise? (OCDE, 2019). Seeking to provide an adequate response to this challenging interrogation, the European Union (EU) has established a series of initiatives to equip individuals with the skills, competences and qualifications required to thrive in such an evolving socio-economic environment. The New Skills Agenda for Europe, the Digital Education Action Plan or the Recommendation on Key Competences for Lifelong Learning, among others, are some examples of such initiatives (European Commission, n.d.).

Following a review of the 2006 European Reference Framework of Key Competences for Lifelong Learning, an updated framework, one that aims at setting out a core set of skills necessary to work and live in the $21^{\text {st }}$ century, was adopted in 2018 . This revised Recommendation on Key Competences for Lifelong Learning emphasizes that "in a rapidly changing and highly interconnected world, each person will need a wide range of skills and competences and to develop them continually throughout life. The key competences, as defined in this reference framework, aim to lay the foundation for achieving more equal and more democratic and inclusive societies. They respond to the need for sustainable growth, social cohesion and further development of the democratic culture" (CEU, 2018). An important reference tool for education and training stakeholders, this Recommendation identifies the following key competences: 1) Literacy competence; 2) Multilingual competence; 3) Mathematical competence and competence in science, technology and engineering; 4) Digital competence; 5) Personal, social and learning to learn competence; 6) Civic competence; 7) Entrepreneurship competence; and 8) Cultural awareness and expression competence. The EU Member States are, thus, encouraged to prepare their citizens for changing labour markets and active citizenship in more diverse, mobile, digital, and global societies, and to develop learning at all stages of life (CEU, 2018; European Commission, 2019).

This paper aims to present a non-formal activity developed with undergraduate students of a Business English Communication course, in collaboration with a group of volunteers from the European Solidarity Corps (ESC). The main objective was to contribute to the development of some of these key competences, especially multilingual skills and cultural sensitivity and expression.

\section{Literature review}

Developing and enhancing human skills and capabilities through education, learning and meaningful work are key drivers of economic success, individual well-being and societal cohesion (WEF, 2020). As Schwab (2016) advises, our ever-evolving reality calls for a response that must be integrated and comprehensive, one that involves all stakeholders of the global polity, from the public and private sectors to civil society and higher education institutions (HEI). In fact, with the aim of better preparing graduates for a demanding job market, major changes have taken place in European 
HEI already. One of the most significant developments is the shift in the learning paradigm: the evolution from traditional, teacher-centred instructional models to learner-centred approaches, where students take an active role in their learning process - that is, in the development or consolidation of their set of competences. The European Council defines "competence" as a combination of knowledge, skills and attitudes. Knowledge is composed of the facts and figures, concepts, ideas and theories which are already established and support the understanding of a certain area or subject; skills are defined as the ability and capacity to carry out processes and use the existing knowledge to achieve results; attitudes refer to the disposition and mind-sets to act or react to ideas, persons or situations (CEU, 2018).

Competences are often divided into two distinct categories: the cognitive and technical competences, also commonly known as "hard skills", and those of a transversal nature, coined as "soft skills". Hard skills refer to easily defined and measured knowledge or abilities that are obtained through (certified) schooling, training, courses and on-the-job training, whereas soft skills, which are often transferable across careers and industries, refer to any skill or quality that can be classified as a personal trait. In other words, these refer to the individual characteristics that shape how individuals communicate with others; personal and interpersonal skills such as active learning, adaptability, creativity, critical thinking, dependability, effective communication, empathy, flexibility, managing feedback, organization, problem-solving, resilience, stress tolerance or teamwork are all important pieces in the set of transferable skills that can be applied in nearly every setting in today's fast-paced global economy (Simões, 2020).

The new reality brought by the Fourth Industrial Revolution calls for a reskilling effort, which to be meaningful requires individuals in general, and HEIs in particular, to adjust and focus on the fastest-growing professions of the future. Alongside engineering, cloud computing, data and AI - all obvious examples of professional areas that will soon be most sought after - people and culture-related jobs, where specialised interpersonal skills are fundamental, will be equally crucial (Zahidi, 2020; Whiting, 2020; WEF, 2020; Desjardins, 2018). According to OECD (2017), to perform these jobs "social intelligence" and "cross-cultural competency" are among the set of

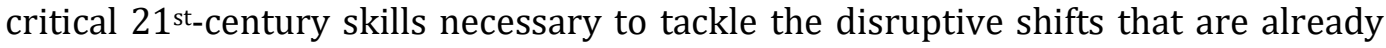
reshaping the workforce landscape.

It is a fact that, more than ever before, the world is characterized by an interrelated, interdependent global community (Samovar, et al., 2013). With the increasing mobility for education, training and work, increasing migration from third countries, and the overall global cooperation, two key competences (CEU, 2018) play a particularly important role in ensuring individuals are up to the challenge: 1) Multilingual competence and 2) Cultural awareness.

On the one hand, the ability to communicate in a language other than one's mother tongue is acknowledged to be one of the key competences which citizens should seek 
to acquire. In the Recommendation on a comprehensive approach to the teaching and learning of languages (CEU, 2019), the Council recommends that EU Member States explore ways to help citizens acquire foreign language (FL) competences in at least one other European language, up to a level that allows them to use the language effectively for social, learning and professional purposes. The acquisition of an additional (third) language, to a level that allows them to interact with a degree of fluency, is also recommended. Above all, this recommendation seeks to reinforce that language skills are a valuable asset that provides competitive advantages for both businesses and job seekers, while simultaneously providing a better understanding of other cultures, thus contributing to the development of citizenship and democratic competences.

As Ninian Smart affirms, "what appears to us as reasonable conclusions from within the perspective of our own culture may, in fact, look different from another cultural perspective" (as cited in Samovar et al. 2013). Therefore, with the current trend towards globalization and internationalisation, not only FL skills but also grasping how international stakeholders think, work, and express themselves through their attitudes and behaviours is also of paramount importance. According to Landau (2018), awareness of how cultural differences can affect business communication is not just helpful, it's essential; organisations that understand and accommodate individuals from different cultural backgrounds are better equipped to scale and build a better reputation amongst such a competitive global market.

With this respect, OCDE stresses the role of this key competence by calling for a global competence education. Global competence can be defined as a "multi-dimensional construct that requires a combination of knowledge, skills, attitudes and values successfully applied to global issues or intercultural situations" (OECD, 2016). As highlighted in the OECD PISA Global Competence Framework (OECD, 2018), globally competent individuals can examine local, global and intercultural issues, understand and appreciate different perspectives and worldviews, interact successfully and respectfully with others, and take responsible action toward sustainability and collective well-being. Moreover, educating for global competence can boost employability, in the sense that effective communication and appropriate behaviour within culturally diverse teams is vital to many international organisations, where employees are also often required to quickly adapt and apply and transfer their skills and knowledge to new contexts.

\section{Methodology}

The activity that shall be presented next was carried out at the Águeda Higher School of Technology and Management, of the University of Aveiro (ESTGA-UA), with a group of undergraduate students of the upper-intermediate level course English Language 
and Business Communication (ELBC). It was planned and organised as a non-formal ${ }^{1}$ initiative, and aimed at addressing two key competences for lifelong learning in particular: the multilingual and the cultural awareness competences.

Through its Youth Center Office, which is one of ESTGA-UA's local partner entities, the city of Águeda has been the host location of several ESC volunteers over the years, in an EU initiative that aims at creating opportunities for young people to work in projects that benefit communities and people around Europe (European Youth Portal, n.d.). In September 2019, the city welcomed volunteers from seven different countries: Austria, England, Spain, Finland, Germany, Greece and the Republic of North Macedonia. Their stay created an excellent opportunity for an invitation to visit the ELBC class and help students link some of the studied conceptual aspects to real testimonials.

This intercultural encounter, which took place on the $12^{\text {th }}$ December 2019, marks the beginning of the project Building Intercultural Bridges in the Classroom, an initiative that aims at involving students in the development of their linguistic and intercultural skills in more active and motivating ways, such as the direct contact with peers from different geographies ${ }^{2}$. Such collaborative experiences not only represent a valuable opportunity to engage students in their own learning process, they also allow for a better understanding of the world through first-hand knowledge. Moreover, as stated in the OECD Future of Education and Skills 2030 Project, such collaborations are perfectly in line with today's vision for the education sector:

Schools are no longer seen as closed entities in themselves, but as part of the larger eco-system in which they operate. Some schools collaborate with each other, forming networks or partnerships with other schools. Some schools have started to collaborate more widely with other organisations in their communities (...), where teachers and students can become familiar with the skills and competencies that employers and other community members deem critical. (OECD, 2019)

With a month to prepare themselves, ELBC students were challenged to organise in groups and present their country and culture to the ESC volunteers. To help each group focus on specific aspects, students were given a list of relevant topics to research (Figure 1) ${ }^{3}$. Above all, the focal point was not so much the information or aspects that can be easily seen/found by non-natives, i.e., the explicit manifestations

\footnotetext{
${ }^{1}$ Whereas formal learning follows a syllabus and is intentional in the sense that learning is the goal of all the activities learners engage in and the learning outcomes are measured by tests or other forms of assessment, non-formal learning takes place outside a formal learning environment but within some kind of organisational framework; the goal is still to develop a particular knowledge and set of skills, but it does not follow a formal syllabus nor is it formally assessed (Council of Europe, n.d.).

2 The project was interrupted in 2020/2021 due to the restrictions imposed by the Covid-19 global pandemic, but a second encounter is already being planned with the Águeda Youth Center for 2021/22. 3 The theoretical framework that supports topics 1.4. and 1.5. - Geert Hofstede's cultural dimensions model and Edward Hall's high and low-context cultural framework - is part of the course syllabus and had been, therefore, extensively discussed in class.
} 
of national culture, rather a reflection upon students' thought patterns and underlying beliefs, attitudes and behaviours, that is to say, all those specific traits that are implicit or out of conscious awareness. When interacting/working across cultures it is precisely this deeper level of culture that leads to difficulties or communication problems that intercultural training seeks to help overcome.

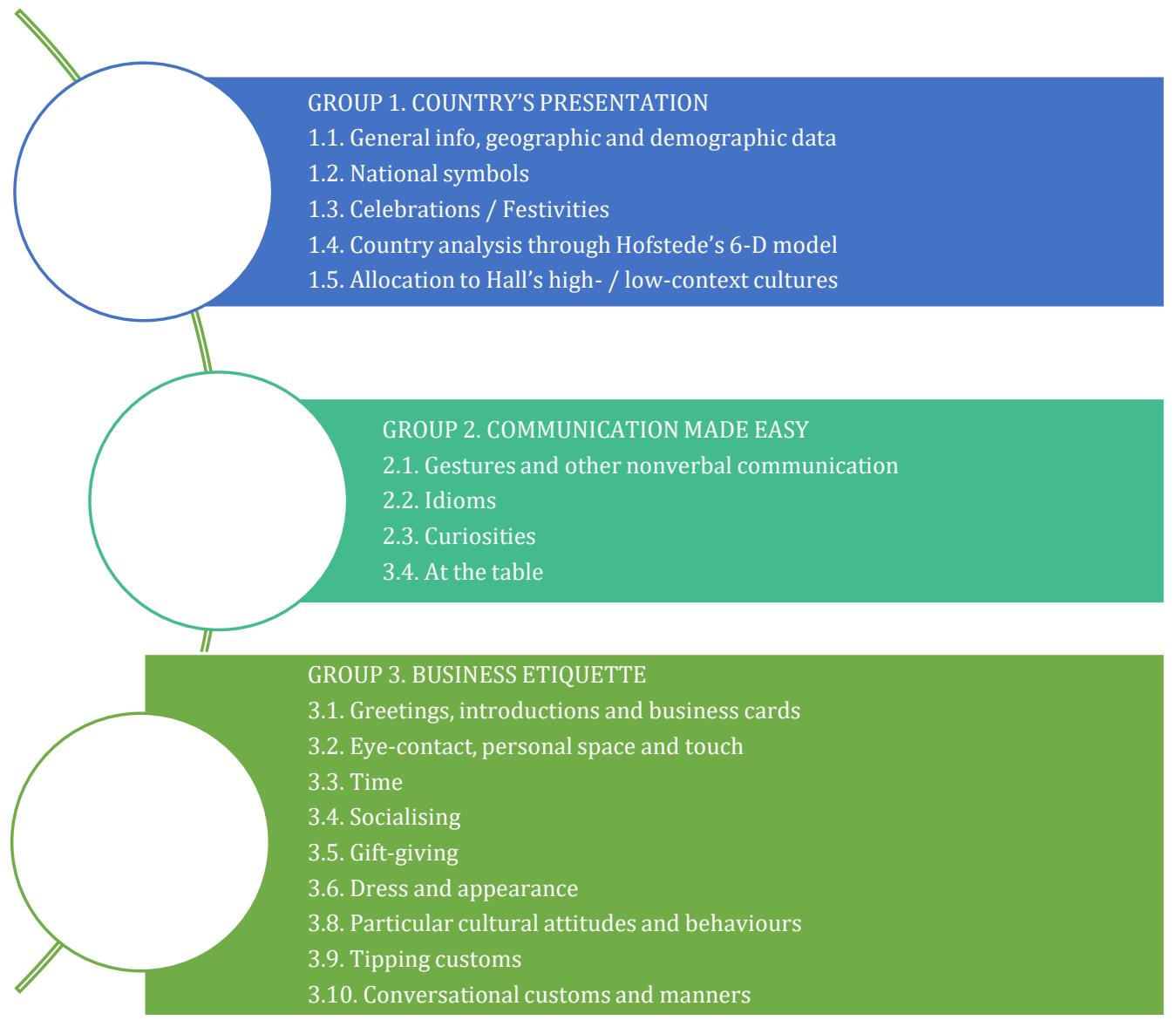

Figure 1 - Profiling Portugal: list of suggested topics

Following the invitation to come to an ELBC class to attend students' presentations, an informal meeting with the ESC volunteers was arranged. After discussing the meaning(s), characteristics and different levels of culture, our visitors were also challenged to present their countries and their national cultures to our students, with a special focus too on the implicit manifestations of their culture, such as, for example, values, attitudes and beliefs, concepts of time and space, authority perception, etc.

The session was organised into three moments: 
Firstly, each group was granted 15 minutes to present their research to the class and ESC volunteers. From creative presentations of factual data, current trends and conceptual frameworks to the showcase of different musical styles (especially those that most likely only locals know about) and the screening of a short film where students portray the Portuguese, with some of our most typical behaviours, cultural habits and funny quirks, colloquialism and curious idioms (Figure 2), the result was a fun yet serious look into ourselves and the matrix - or the "cultural programming of the mind" (Hofstede, 2005) - we are all built upon.

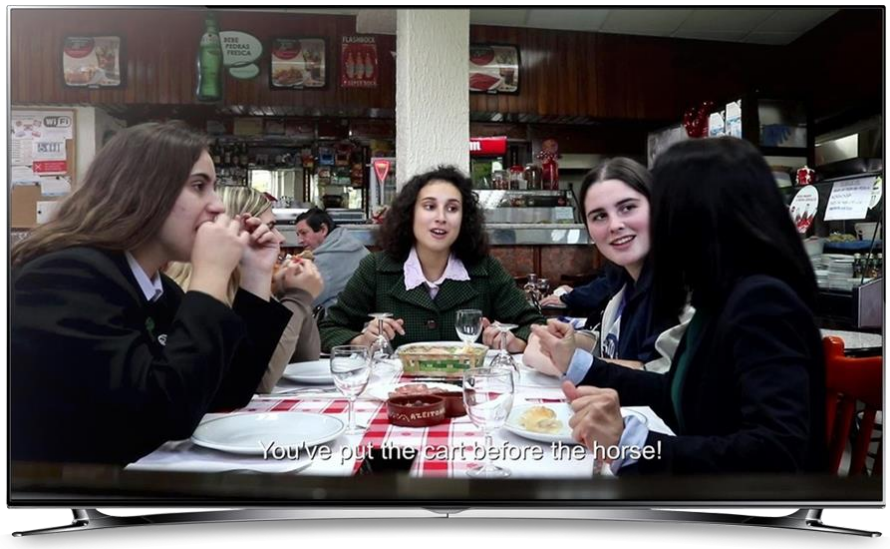

Figure 2 - Screenshot of the film "Friends getting together at a Portuguese tavern" (written, played and edited by students)

Students' presentations were followed by a coffee break where a variety of traditional products (proudly) brought by students from their hometowns was served. In a culture where food and gathering around the table are a central part of social relationships and many rituals, this moment was particularly symbolic and meaningful. It also provided students and ESC volunteers with the opportunity to comment on students' presentations and socialize and interact in a relaxed, informal way. Afterwards, the floor was given to the ESC volunteers, who participated enthusiastically in the task by introducing their countries to the attendees. Overall, each one of them conducted a candid self-analysis, which revealed the volunteers' creativity as well as their ability to laugh at themselves and, above all, demonstrated how culture does shape the way we act in our daily lives, see the world and interact with others.

After the end of the semester, students were invited to answer an online questionnaire, which was anonymous and included 16 items that aimed at assessing the overall learning experience, as well as students' perceptions regarding the development of specific skills. Answering the questionnaire was not mandatory and data from the 19 participating students were collected. 


\section{Results}

The applied questionnaire was divided into three sections: 1) the overall learning experience; 2) hard and soft skills development; 3) future initiatives and improvement suggestions.

In section I, the response to the first question - Did this activity help you relate the intercultural communication concepts and theories discussed in class with the reality presented by our visitors? - was $100 \%$ positive. As for question 2 - Which stage(s) of the activity do you consider most interesting and/or rewarding? (Figure 3) -, to learn about our visitors' cultural background (94.7\%) and the interaction moment (84.2\%) were the most selected options. 57.9\% of the students also selected the group interaction and the preparation of activity for the event day. The nervousness and unease usually inherent to public speaking, especially in such group age (18/19-yearolds), might have influenced the lower results of the fourth option, the presentation delivery.

To listen and learn about our visitors' cultural background

The coffee break \& the interaction

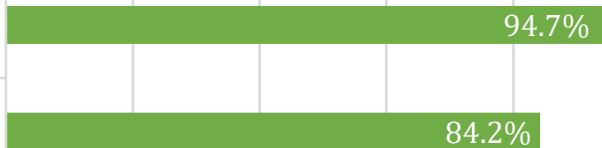

The actual presentation

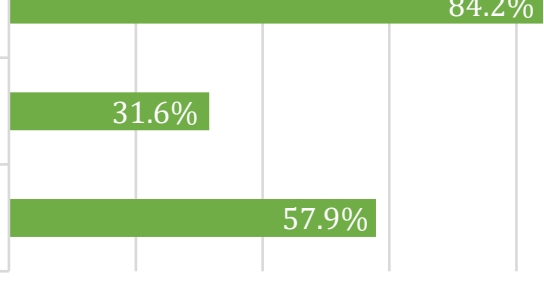

To interact with my group and prepare the activity

Figure 3 - The most interesting and/or rewarding aspect(s) of the activity

As for question 3 - How do you feel about being involved in an activity with no reflection on your final grade? - 17 students considered that every experience is a learning opportunity, regardless if it's part or not of the formal evaluation. 2 students mentioned that they would have preferred to be formally graded for their work, even though that's not reason enough to not participate. Above all, students seem to recognise the intrinsic value of such experiences where it is not all about immediate outcomes, rather about processes that contribute to personal and academic improvement. Regarding the fourth question - On a scale from 1-5, with 1 being 'very bad' and 5 'very good', what's your overall assessment of the activity? - the results are very positive with over two-thirds of the class (78.5\%) considering it a 'very good' experience and the remaining $21.5 \%$ assessing it as a 'good' one.

Section II aimed to assess how this activity contributed to the development of specific skills. A Likert-like scale from 1 to 5 was used for every item and data analysis shows 
that, on average, students consider the accomplishment of the activity as being very positive.

As can be observed in Figure 4, skills of a more cognitive and functional nature are assessed with mean values above 4. According to students' perception, research and information selection skills is the most developed item (4.3); all other items are assessed with 4.2. As shown in Table 1, for every assessed item, the value that occurs the highest number of times (mode) is 5.0. General vocabulary expansion (standard deviation 1.1) and Overall improvement of communication skills (standard deviation 1.0) are the items where opinions most diverged, which can be justified with the actual group's heterogeneity in terms of language proficiency level. Nevertheless, the remaining results are quite consistent with all minimum and maximum values between 3.0 and 5.0 .

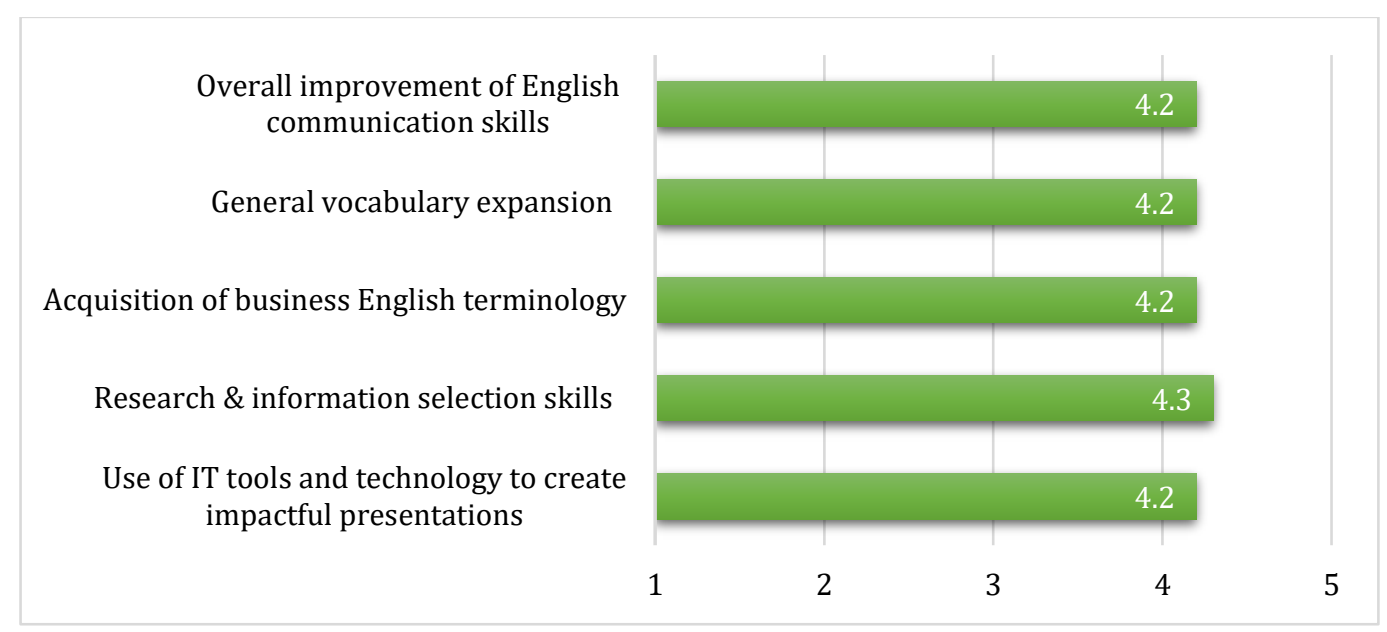

Figure 4. Developed hard skills: students' perception (mean values)

Table 1 - Developed cognitive and functional skills: mean, standard deviation, minimum and maximum, mode and median values

$\begin{array}{lllll}\begin{array}{l}\text { Overall } \\ \text { improvement } \\ \text { of English } \\ \text { communicatio }\end{array} & \begin{array}{l}\text { General } \\ \text { vocabulary } \\ \text { n skills }\end{array} & \begin{array}{l}\text { Acquisition } \\ \text { of business } \\ \text { English } \\ \text { terminology }\end{array} & \begin{array}{l}\text { Improvemen } \\ \text { t of research } \\ \text { \& } \\ \text { information } \\ \text { selection } \\ \text { skills }\end{array} & \begin{array}{l}\text { Use of IT to } \\ \text { create } \\ \text { impactful } \\ \text { presentation } \\ \text { S }\end{array} \\ 4.2 & 4.2 & 4.2 & 4.3 & 4.2 \\ 1.0 & 1.1 & 0.9 & 0.9 & 0.8 \\ 4.0 & 5.0 & 4.0 & 5.0 & 4.0 \\ 5.0 & 5.0 & 5.0 & 5.0 & 5.0 \\ 5.0 & 5.0 & 5.0 & 5.0 & 5.0 \\ 2.0 & 1.0 & 3.0 & 3.0 & 3.0\end{array}$


Concerning the self-assessment of the developed interpersonal and social competencies, Teamwork (4.7), Creativity (4.6) and Recognition of cultural differences (4.6) received the most positive ratings (Figure 5).

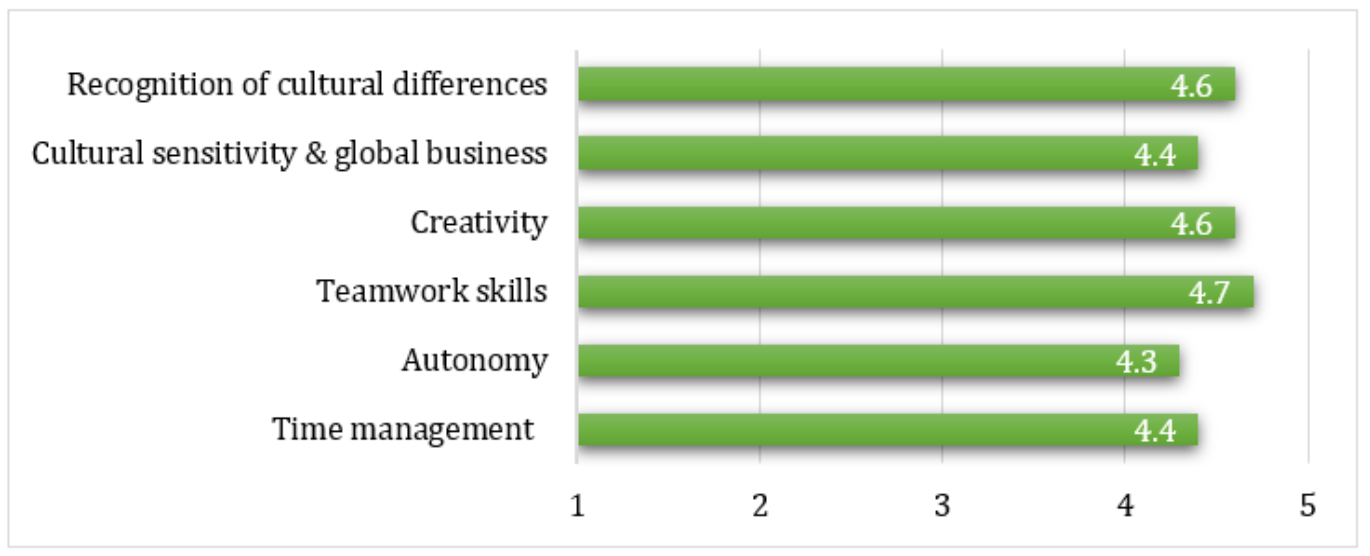

Figure 5. Developed interpersonal and social skills: students' perception (mean values)

As shown in Table 2, with minimum and maximum values between 4.0 and 5.0 and a standard deviation of 0.5 , students' opinions are convergent. With 4.4 , the recognition of the impact of cultural differences on international business interactions is another positively developed/consolidated competency, with $63 \%$ of the respondents giving it a score of 5.0. Similarly to the previous set of competencies, for every assessed soft skill, the mode is also 5.0.

Table 2: Interpersonal and social skills: mean, standard deviation, minimum and maximum, mode and median values

\begin{tabular}{|c|c|c|c|c|c|}
\hline $\begin{array}{l}\text { Recognitio } \\
\mathrm{n} \text { of cultural } \\
\text { differences }\end{array}$ & $\begin{array}{l}\text { Cultural } \\
\text { sensitivity } \\
\& \text { global }\end{array}$ & Creativity & $\begin{array}{l}\text { Teamwor } \\
\text { k skills }\end{array}$ & Autonomy & $\begin{array}{l}\text { Time } \\
\text { manage- } \\
\text { ment }\end{array}$ \\
\hline
\end{tabular}

$\begin{array}{lllllll}\text { Mean } & 4.6 & 4.4 & 4.6 & 4.7 & 4.3 & 4.4 \\ \text { SD } & 0.5 & 0.8 & 0.5 & 0.5 & 0.9 & 0.9 \\ \text { Median } & 5.0 & 5.0 & 5.0 & 5.0 & 5.0 & 5.0 \\ \text { Mode } & 5.0 & 5.0 & 5.0 & 5.0 & 5.0 & 5.0 \\ \text { Max. } & 5.0 & 5.0 & 5.0 & 5.0 & 5.0 & 5.0 \\ \text { Min. } & 4.0 & 3.0 & 4.0 & 4.0 & 2.0 & 2.0\end{array}$

In the final section of the questionnaire, students were asked to leave a comment and refer to the possibility of repeating the initiative in future editions of the course (open 
question). The overall opinion is that the initiative had such a positive impact it should again be implemented in the future. Next, a sample of students' final feedback:

- "It was an excellent activity that should be repeated next year! It makes us practise everything we learn in English classes, including learning new cultures."

- "It is always great to meet new people and learn more about other countries."

- "I think it is a good activity for us to interact with people from other cultures, thus learning more about these cultures."

- "Close contact with other cultural realities is an excellent way to assimilate knowledge and share experiences in the first person."

- "I loved learning a little about other languages and cultures. I think that this experience is very enriching for our professional future."

- "These initiatives help a lot to understand how other cultures and countries work and it's interesting to meet people who have completely different perspectives from ours."

\section{Discussion}

Considering students' concrete performance in terms of the conducted research, content and materials creation and oral presentations/interactions, as well as their positive feedback on the developed activities, it can be considered that the proposed activity was effective, with a beneficial impact on both academic achievement and personal growth. On the one hand, some of the formal learning outcomes established for the ELBC curricular unit were successfully addressed, namely

a) the production of oral and written texts in English

b) the development of research in the field of intercultural communication

c) the oral presentation of the results of this research

d) the production and optimisation of oral and written texts through the use of online/IT tools.

On the other hand, the proposed assignment allowed students to develop their linguistic and intercultural communication skills through teamwork and collaboration, by creating content and presenting it to an audience, which contributes to the development of a broader set of critical knowledge and competences. Communication and interaction skills, organisation skills, initiative and creativity, assertiveness and problem-solving techniques, or negotiation and conflict resolution skills - all attributes that are highly valued in real-world scenarios - were, on a level or another, developed/consolidated through the activity. For some students though, autonomy and time management seemed more difficult to navigate effectively, which demonstrates that more practical activities are necessary to more adequately prepare learners for the demands of the current workplace, where not rarely professionals are asked to multitask under tight deadlines. 


\section{Conclusions and Final Remarks}

All in all, by assuming an active rather than passive role in the learning process, such learner-centred activities represent an opportunity for students to enter the workforce with experience in the areas of research, team cooperation, even critical thinking and project management, which will constitute a competitive advantage once these graduates enter the labour market. Moreover, creating opportunities for students to engage with both local organisations and individuals from diverse linguistic and cultural backgrounds allows for a better understanding of their community and the world, which not only contributes to the development of core employability skills, but also strengthens their sense of belonging and active citizenship.

On a final note, and despite being at the heart of EU's vision to create a European Education Area, the importance of FL skills and cross-cultural competency is still not fully considered, especially at some HEI, where FL courses are not included in curricular plans where FL mastery would be a major asset for students - or even systematically suppressed from plans undergoing reformulation. The option for core contents instead of investing in transferable skills that would better equip students for the global economy seems to be an ongoing trend, probably based on the incorrect assumption that language skills acquired before the end of secondary education are sufficient enough. They are not, as only four in ten learners in secondary education reach the "independent user'" level in their first foreign language (CEU, 2019). It is, therefore, recommended to look at these options more cautiously and reflect whether we are indeed preparing our students for a future where they have to quickly adapt regardless of what life throws their way.

\section{References}

[1] Council of Europe (n.d.). Formal, non-formal and informal learning. LIAM project, keywords. Retrieved August 20, 2021, from https://www.coe.int/en/web/lang-migrants/formal-non-formal-andinformal-learning.

[2] CEU (2019). Council recommendation of 22 May 2019 on a comprehensive approach to the teaching and learning of languages. Official Journal of the European Union, 189, 5.6.2019, pp.15-20.

[3] CEU (2018). Council recommendation of 22 May 2018 on key competences for lifelong learning. Official Journal of the European Union, 189, 4.6.2018, p. $1-13$.

[4] Desjardins, J. (2018). 10 skills you'll need to survive the rise of automation. World Economic Forum. Retrieved August 20, 2021, from https://www.weforum.org/agenda/2018/07/the-skills-needed-tosurvive-the-robot-invasion-of-the-workplace.

[5] European Commission (2019). Supporting Key Competence Development: Learning approaches and environments in school education. Retrieved 
August 20, 2021, from https://ec.europa.eu/education/resources-andtools/document-library/supporting-key-competence-developmentlearning-approaches-and-environments-in-school-education-conferencereport_en.

[6] European Commission (n.d.). The importance of key competences development. Retrieved August 20, 2021, from

https://ec.europa.eu/education/policies/european-policycooperation/development-skills_en.

[7] European Youth Portal (n.d.). What is the European Solidarity Corps? Retrieved August 20, 2021, from https://europa.eu/youth/solidarity_en.

[8] Hofstede, G. (2005). Cultures, and Organizations: Software of the Mind, $2^{\text {nd }}$ ed. McGraw-Hill.

[9] Landau, J. (2018). Why cultural sensitivity should be a forethought, not an afterthought, Forbes, 17 October. Retrieved August 20, 2021, from https://www.forbes.com/sites/forbesnycouncil/2018/10/17/whycultural-sensitivity-should-be-a-forethought-not-anafterthought/\#3d653fb61b69.

[10] OECD (2019). OECD future of education and skills 2030. OECD Learning Compass 2030. Retrieved August 20, 2021, from ttps://www.oecd.org/education/2030-project/.

[11] OECD (2018). Preparing our youth for an inclusive and sustainable world. The OECD Pisa Global Competence Framework. Retrieved August 20, 2021, from https://www.oecd.org/pisa/Handbook-PISA-2018-GlobalCompetence.pdf.

[12] OECD (2017). 21st Century Skills: Learning for the Digital Age. Retrieved August 20, 2021, from https://www.oecd-forum.org/posts/20442-21stcentury-skills-learning-for-the-digital-age.

[13] OECD. (2016). Global competency for an inclusive world. Paris, France. Retrieved August 20, 2021, from http://www.oecd.org/pisa/pisa-2018global-competence.htm.

[14] Sala, A., Punie, Y., Garkov, V. and Cabrera Giraldez, M. (2020). LifeComp: The European Framework for Personal, Social and Learning to Learn Key Competence. Publications Office of the European Union, Luxembourg.

[15] Samovar, L., Porter, R., McDaniel, E. \& Roy, C. (2013). Communication Between Cultures [Eighth Edition]. Wadsworth: Cengage Learning.

[16] Simões, A. (2020). Preparing students for the global workplace: classroom strategies for developing English and intercultural communication skills. Proceedings of Iceri2020 Conference, pp. 7962-7971.

[17] Schwab, K. (2016). The Fourth Industrial Revolution: what it means, how to respond. World Economic Forum. Retrieved August 20, 2021, from https://www.weforum.org/agenda/2016/01/the-fourth-industrialrevolution-what-it-means-and-how-to-respond. 
[18] Whiting, K. (2020). These are the top 10 job skills of tomorrow - and how long it takes to learn them. World Economic Forum. Retrieved August 20, 2021, from https://www.weforum.org/agenda/2020/10/top-10-workskills-of-tomorrow-how-long-it-takes-to-learn-them/.

[19] WEF (2020). The Future of Jobs Report 2020. World Economic Forum.

[20] Zahidi, S. (2020). We need a global reskilling revolution - here's why. World Economic Forum. Retrieved August 20, 2021, from https://www.weforum.org/agenda/2020/01/reskilling-revolution-jobsfuture-skills/. 